\title{
NANOFILTRAÇÃO PARA TRATAMENTO DE ÁGUAS RESIDUÁRIAS DE MINERAÇÃO DO OURO
}

\author{
L. H. ANDRADE ${ }^{1}$, A. O. AGUIAR ${ }^{1}$, W. L. PIRES ${ }^{1}$, M. C. S. AMARAL ${ }^{1}$ \\ ${ }^{1}$ Universidade Federal de Minas Gerais, Departamento de Engenharia Sanitária e Ambiental \\ E-mail para contato: lauraha@ymail.com
}

RESUMO - Esse trabalho objetivou avaliar a aplicação de nanofiltração (NF) como tecnologia para tratamento e reuso de duas águas residuárias da produção de ouro: a drenagem ácida de mina (DAM) e o efluente da planta de produção de ácido sulfúrico (EF). A NF foi aplicada às águas residuárias brutas, pré-filtradas com filtro qualitativo e pré-filtradas com microfiltração, e seu desempenho foi avaliado em termos de incrustação e qualidade do efluente tratado (concentração de íons, metais, sólidos totais e condutividade elétrica). Os resultados mostraram que a filtração das duas águas residuárias estudadas não acarreta grande incrustação da membrana de NF, mesmo quando o efluente bruto, sem pré-tratamento, é utilizado. O fluxo de efluente variou entre 62 e $90 \%$ do fluxo da membrana limpa com água. As eficiências de remoção de sólidos (> $80 \%)$, condutividade (>96\%), sulfato (>99\%) e cálcio (>99\%), principais contaminantes dos efluentes, foram bastante elevadas. Observou-se que a aplicação de pré-tratamento melhora não só a eficiência global de remoção de poluentes como também o fluxo de permeado médio.

\section{INTRODUÇÃO}

A mineração e o processamento de minérios a base de ouro são atividades de grande importância econômica. Devido às suas propriedades físico-químicas, o ouro tem sido empregado em diversas aplicações, que vão desde a fabricação de joias até a cobertura protetora de satélites e o uso medicinal. Por outro lado, a explotação e o processamento desse material leva a impactos ambientais que variam desde destruição de habitats naturais e consequente perda de biodiversidade até a disposição de grande quantidade de rejeito no ambiente.

Um impacto relevante é a geração e o descarte da drenagem ácida de mina (DAM). De acordo com Kontopoulo (1998) e Silva (2009), a DAM resulta de uma série complexa de reações químicas envolvendo oxidação direta ou indireta dos minerais sulfetados (em geral pirita) em presença de água e oxigênio, liberando acidez e sulfato para o meio. Essa reação pode ser catalisada por cátions metálicos e bactérias, tais como Thiobacillus Ferroxidans, aumentando expressivamente a taxa de reação. Os impactos da DAM no meio ambiente incluem acidificação de águas superficiais e subterrâneas e de solos, diminuição da biodiversidade, solubilização de metais pesados, que poderão atingir o homem na cadeia alimentar através da bioacumulação e biomagnificação, geração de precipitados nos corpos d'água prejudicando a flora bentônica, entre outros (BORMA e SOARES, 2002; SILVA, 2009). 


\section{9 a 22 de outubro de 2014 \\ Florianópolis/SC}

Ainda que a drenagem de mina seja a água residuária mais estudada da mineração, existem outros efluentes, provenientes das etapas de beneficiamento e processamento dos minérios, que também merecem atenção. Uma dessas águas residuárias é o efluente da planta de produção de ácido sulfúrico. A ustulação, um processo normalmente encontrado na etapa de beneficiamento pirometalúrgico do ouro, consiste na calcinação do minério concentrado, gerando gases que contém alta concentração de SO2. Esses gases podem ser oxidados e solubilizados, gerando ácido sulfúrico. Nesse processo é gerado um efluente (EF) que, devido às suas características, como elevada acidez, presença de metais pesados e alta concentração de arsênio, deve ser devidamente tratado antes de ser descartado nos corpos d'água.

Os processos de separação por membranas (PSM) são sistemas que utilizam uma barreira seletiva (membrana) que sob a ação de uma força motriz promove a separação de determinados componentes de uma solução ou suspensão. Os PSM podem ser considerados tecnologias promissoras para o tratamento dessas duas águas residuárias da mineração do ouro (drenagem ácida de mina e efluente da planta de produção de ácido sulfúrico) devido às suas vantagens frente aos processos convencionais, tais como elevada eficiência, facilidade de escalonamento e baixo requisito de área. (HABERT et al., 2006).

Uma vez que a maior parte dos contaminantes dos efluentes da mineração são ânions ou cátions metálicos, para seu tratamento devem ser utilizados processos capazes de reter sais e moléculas dissolvidas, como a nanofiltração (NF). Por ser um PSM intermediário entre a ultrafiltração e a osmose inversa, a NF apresenta as vantagens de ambos, como elevada eficiência de retenção de sais e baixos requisitos de pressão ( 5 a 25 bar). Estudos mostram que a NF é um sistema eficiente para o tratamento secundário ou terciário de efluentes visando à geração de água para reúso industrial, agrícola e/ou potável indireto (SHU et al., 2005; ACERO et al., 2010).

Dessa forma, o objetivo do presente trabalho foi avaliar a aplicação de nanofiltração (NF) como tecnologia para tratamento e reúso de duas águas residuárias da produção de ouro: a drenagem ácida de mina (DAM) e o efluente da planta de produção de ácido sulfúrico (EF).

\section{MATERIAIS E MÉTODOS}

\subsection{Amostras}

As amostras utilizadas nesse trabalho (drenagem ácida de mina e efluente da planta de produção de ácido sulfúrico) foram coletadas em uma mina de ouro em operação no interior de Minas Gerais.

\subsection{Descrição da unidade de NF}

Para os testes foram utilizadas a membrana de nanofiltração NF90 adquirida da empresa Dow Filmtech, constituída por um compósito de poliamida, e uma célula de aço inoxidável de $8,9 \mathrm{~cm}$ de diâmetro, proporcionando uma área de filtração de $62 \mathrm{~cm}^{2}$. O sistema de filtração de NF era composto por um tanque de alimentação, uma bomba conectada a um controlador de velocidade, rotâmetro para leitura da vazão de alimentação, válvula para ajuste da pressão, manômetro e medidor de temperatura. 


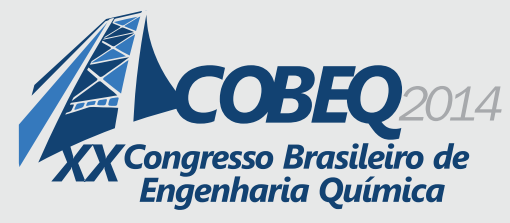

19 a 22 de outubro de 2014
Florianópolis/SC

A vazão de permeado era medida através da coleta do volume de permeado em uma proveta durante um determinado tempo

\subsection{Avaliação da NF para tratamento das águas residuárias}

A nanofiltração (NF) das amostras de DAM e EF foi testada com a utilização de dois tipos diferentes de pré-tratamentos: filtração com membranas de microfiltração (Pam Membranas Seletivas, membrana de polieterimida, $0,044 \mathrm{~m}^{2}$, diâmetro médio de poros $0,4 \mu \mathrm{m}$ ) e filtração com filtro de papel qualitativo (equivalente à filtração com filtro tipo cartucho convencional); e sem pré-tratamento (efluente bruto). As amostras com e sem pré-tratamento foram nanofiltradas durante um período de 2 horas, a pressão de 10 bar e vazão de alimentação de 2,4 L/min. O fluxo de permeado foi acompanhado com intervalos de medição de 15 minutos. O permeado final foi caracterizado em relação a sólidos totais (ST), condutividade elétrica, ânions $\mathrm{SO}_{4}{ }^{2-}, \mathrm{Cl}^{-}, \mathrm{NO}_{3}{ }^{-}$(Cromatógrafo iônico DIONEX AG4A) e metais (Espectrofotômetro de massa com plasma acoplado indutivamente). As amostras de efluente da planta de produção de ácido sulfúrico bruto e de seus respectivos permeados de NF também foram analisadas quanto a concentração de arsênio por absorção atômica.

\section{RESULTADOS E DISCUSSÃO}

A Figura 1 apresenta a variação do fluxo de permeado com o tempo para a nanofiltração da DAM com e sem pré-tratamento (bruto - sem pré-tratamento; qualitativo - pré-filtração em filtro qualitativo; $\mathrm{MF}$ - pré-filtração com microfiltração). No gráfico, é mostrado o valor do fluxo de permeado $\left(\mathrm{J}_{\text {efluente }}\right)$ dividido pelo fluxo com água $\left(\mathrm{J}_{\text {água }}\right)$ da membrana limpa, medidos na mesma pressão. Essa relação foi calculada com a finalidade de evitar que mudanças na característica da membrana (pequenas alterações na permeabilidade hidráulica) influenciassem a análise do fluxo de permeado. $\mathrm{O}$ erro das medidas de fluxo $\left( \pm 0,85 \mathrm{~L} / \mathrm{h} . \mathrm{m}^{2}\right)$ equivale a aproximadamente $2 \%$ do fluxo da membrana com água. Pode-se observar baixa ocorrência de incrustação durante a nanofiltração da DAM, o que é evidenciado através dos altos valores de $\mathrm{J}_{\text {efluente }} / \mathrm{J}_{\text {água }}$ (entre 62 e $84 \%$ ) encontrados para todo o período de filtração. Isso pode estar relacionado às baixas concentrações de compostos incrustantes, tais como sólidos suspensos e matéria orgânica, na alimentação $(25 \mathrm{mg} / \mathrm{L}$ de sólidos suspensos totais e 2,0 mg/L de carbono orgânico total (COT)). A média do fluxo de permeado encontrada nesse teste foi $36 \mathrm{~L} / \mathrm{h} . \mathrm{m}^{2}$, que é considerado um fluxo bastante elevado para filtração de efluentes e águas residuárias industriais.

Nota-se que o tipo de pré-tratamento aplicado não influenciou significativamente o desempenho da membrana em termos de incrustação, provavelmente devido à baixa concentração de sólidos suspensos na alimentação. Entretanto, uma vez que a frequência de limpeza e manutenção e a vida útil das membranas são influenciadas diretamente pela presença de material suspenso no interior dos módulos, e que as características de efluentes industriais podem sofrer alterações com o tempo, é usual a aplicação de pré-tratamento com, no mínimo, filtro cartucho. Se houver interesse em se instalar NF para um efluente industrial sem pré-tratamento, uma avaliação mais profunda, com testes contínuos em uma planta piloto, deverá ser feita. 


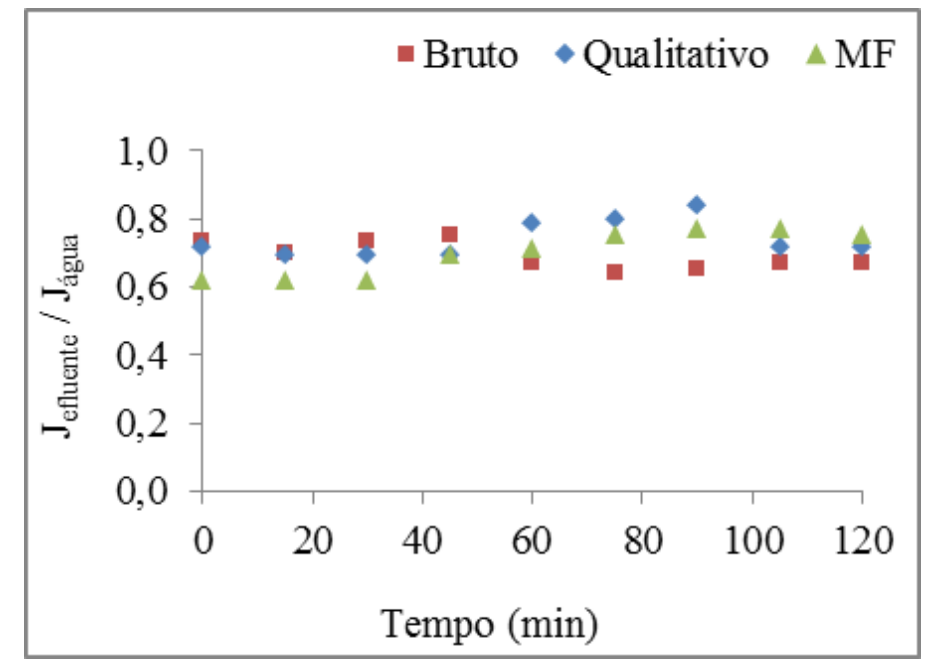

Figura 1 - Fluxo de permeado dividido pelo fluxo com água ao longo do tempo de filtração através da membrana de NF para DAM bruta e pré-tratada com MF e filtro qualitativo.

A Tabela 1 apresenta as características do permeado da NF da DAM obtidas com e sem prétratamentos.

Tabela 1 - Qualidade dos permeados obtidos pela de NF da DAM bruta e pré-tratada com MF e filtro qualitativo

\begin{tabular}{|c|c|c|c|c|c|c|}
\hline \multicolumn{2}{|c|}{ Amostra } & $\begin{array}{c}\text { Condutividade } \\
\text { elétrica } \\
\left(\mathrm{mS} / \mathrm{cm}^{2}\right)\end{array}$ & $\begin{array}{c}\text { Sólidos totais } \\
(\mathrm{mg} / \mathrm{L})\end{array}$ & $\begin{array}{c}\mathrm{SO}_{4}{ }^{2-} \\
(\mathrm{mg} / \mathrm{L})\end{array}$ & $\begin{array}{c}\mathrm{Cl}^{-} \\
(\mathrm{mg} / \mathrm{L})\end{array}$ & $\begin{array}{c}\mathrm{NO}_{3}{ }^{-} \\
(\mathrm{mg} / \mathrm{L})\end{array}$ \\
\hline \multicolumn{2}{|c|}{ DAM bruta (mg/L) } & 2,250 & 2.409 & 984,5 & 4,5 & 6,5 \\
\hline $\begin{array}{c}\text { Permeado } \\
\text { (Sem pré- } \\
\text { tratamento) }\end{array}$ & $\begin{array}{c}\text { Concentração } \\
(\mathrm{mg} / \mathrm{L})\end{array}$ & 0,056 & 495 & 7,2 & 1,4 & 2,5 \\
\cline { 2 - 8 } & Remoção & $98 \%$ & $79 \%$ & $99 \%$ & $68 \%$ & $62 \%$ \\
\hline $\begin{array}{c}\text { Permeado } \\
\text { (Filtração com } \\
\text { filtro qualitativo) }\end{array}$ & $\begin{array}{c}\text { Concentração } \\
\text { (mg/L) }\end{array}$ & 0,036 & 483 & 6,7 & 1,1 & 1,8 \\
\cline { 2 - 8 } & Remoção & $99 \%$ & $80 \%$ & $99 \%$ & $76 \%$ & $73 \%$ \\
\hline $\begin{array}{c}\text { Permeado } \\
\text { (Filtração com } \\
\text { microfiltração) }\end{array}$ & $\begin{array}{c}\text { Concentração } \\
\text { (mg/L) }\end{array}$ & 0,031 & 293 & 5,2 & 1,2 & 1,9 \\
\cline { 2 - 8 } & Remoção & $99 \%$ & $88 \%$ & $99 \%$ & $74 \%$ & $71 \%$ \\
\hline
\end{tabular}

Nota-se que a NF é um processo bastante eficiente para a remoção de sais. A condutividade do permeado foi reduzida em $98 \%$ em relação ao efluente bruto, e os sólidos totais, 80 a $88 \%$. O próprio 
processo de formação da DAM faz com que a quantidade de sulfato presente nessa água residuária seja elevada, chegando a quase $1 \mathrm{~g} / \mathrm{L}$ na amostra estudada. Apesar disso, o sistema se mostrou bastante eficiente para remoção desse ânion (99\% de remoção), o que condiz com os resultados encontrados por outros autores (KRIEG et al., 2004). As retenções de cloreto e nitrato, embora possam ser consideradas satisfatórias, são menores que as de sulfato. Isso ocorre devido ao efeito Donnan, que determina que quando diferentes íons passam através uma membrana de mesma carga superficial, aqueles de menor valência irão permear preferencialmente (NGUYEN et al., 2009).

As concentrações de diversos metais da DAM bruta e do permeado da NF após pré-tratamento com MF foram quantificadas e os resultados são apresentados na Tabela 2. Os principais metais encontrados na DAM são cálcio, magnésio, manganês, alumínio, sódio e zinco. Porém, os mesmo apresentam baixas concentrações no permeado da NF, o que mostra, mais uma vez, o alto desempenho desse processo para a retenção de contaminantes.

Tabela 2 - Concentração dos principais metais encontrados na DAM bruta e no permeado da NF com pré-tratamento com MF

\begin{tabular}{|c|c|c|c|}
\hline \multirow{2}{*}{ Metal } & \multicolumn{2}{|c|}{ Concentração (mg/L) } & $\begin{array}{c}\text { Eficiência } \\
\text { de remoção }\end{array}$ \\
\cline { 2 - 3 } & DAM & Permeado & $99 \%$ \\
\hline Alumínio Total & 11,1 & 0,15 & $99 \%$ \\
\hline Cálcio Total & 282 & 2,74 & $99 \%$ \\
\hline Magnésio Total & 125 & 1,19 & $99 \%$ \\
\hline Manganês Total & 23,7 & 0,16 & $>85 \%$ \\
\hline Sódio Total & 5,68 & $<0,8$ & $95 \%$ \\
\hline Zinco Total & 3,25 & 0,17 & \\
\hline
\end{tabular}

O teste de NF foi também realizado para amostras de EF. A Figura 2 apresenta a variação do fluxo de permeado com o tempo. Os valores de $\mathrm{J}_{\text {efluente }} / \mathrm{J}_{\text {água }}$ variaram entre $90 \%$ e $65 \%$. Nota-se um decaimento do fluxo ao longo do tempo, porém com uma tendência à estabilização em valores de $\mathrm{J}_{\text {efluente }} / \mathrm{J}_{\text {água }}$ entre 0,70 e 0,65. A amostra bruta apresentou um decaimento de fluxo mais rápido e acentuado que as outras que receberam pré-tratamento, indicando a necessidade de adoção de préfiltração convencional ou com microfiltração anterior à NF. Esse resultado, contrário ao observado para a DAM, pode estar relacionado à maior concentração de sólidos suspensos dessa corrente (sólidos suspensos totais $=43 \mathrm{mg} / \mathrm{L}$ ). 


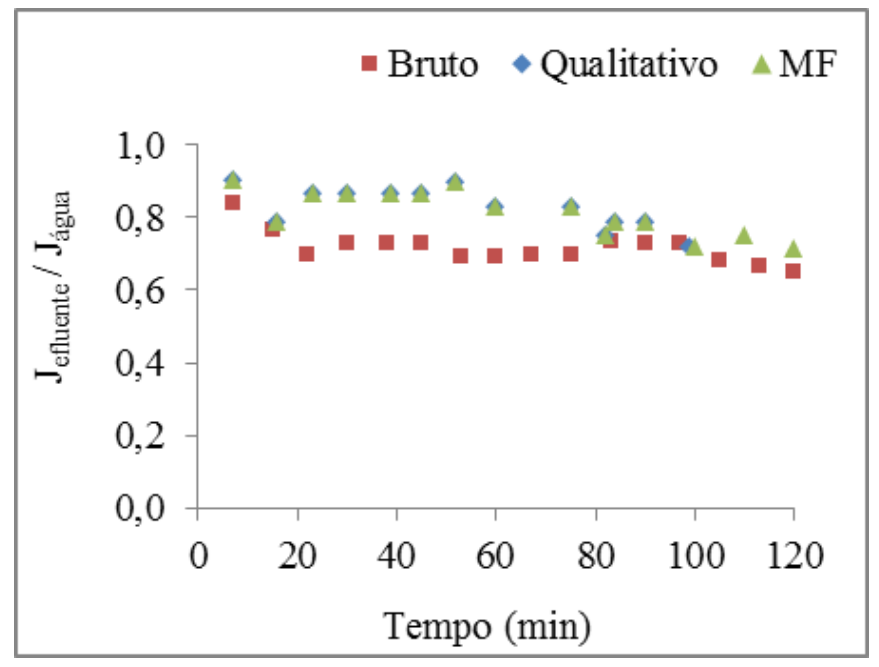

Figura 2 - Fluxo de permeado dividido pelo fluxo com água ao longo do tempo de filtração através da membrana de NF para EF bruto e pré-tratado com MF e filtro qualitativo.

A Tabela 3 apresenta as características dos permeados da NF do EF obtidos com os três diferentes pré-tratamentos.

Tabela 3 - Qualidade dos permeados obtidos pela de NF do EF bruto e pré-tratado com MF e filtro qualitativo

\begin{tabular}{|c|c|c|c|c|c|c|c|}
\hline \multicolumn{2}{|c|}{ Amostra } & $\begin{array}{c}\text { Condutividade } \\
\text { elétrica } \\
\left(\mathrm{mS} / \mathrm{cm}^{2}\right)\end{array}$ & $\begin{array}{c}\text { Sólidos } \\
\text { totais } \\
(\mathrm{mg} / \mathrm{L})\end{array}$ & $\begin{array}{c}\mathrm{SO}_{4}{ }^{2-} \\
(\mathrm{mg} / \mathrm{L})\end{array}$ & $\begin{array}{c}\mathrm{Cl}^{-} \\
(\mathrm{mg} / \mathrm{L})\end{array}$ & $\begin{array}{c}\mathrm{NO}_{3}{ }^{-} \\
(\mathrm{mg} / \mathrm{L})\end{array}$ & $\begin{array}{c}\text { Arsênio } \\
(\mathrm{mg} / \mathrm{L})\end{array}$ \\
\hline \multicolumn{2}{|c|}{ EF bruto (mg/L) } & 14,27 & 9.054 & 3060,8 & 4,4 & 2,1 & 472,1 \\
\hline $\begin{array}{c}\text { Permeado } \\
(\text { Sem pré- } \\
\text { tratamento) }\end{array}$ & $\begin{array}{c}\text { Concentração } \\
(\mathrm{mg} / \mathrm{L})\end{array}$ & 0,60 & 381 & 44,1 & 5,9 & 2,3 & 81,0 \\
\cline { 2 - 9 } $\begin{array}{c}\text { Remoção } \\
\text { (Filtração com } \\
\text { filtro }\end{array}$ & $\begin{array}{c}\text { Concentração } \\
\text { (mg/L) }\end{array}$ & $06 \%$ & $96 \%$ & $99 \%$ & - & - & $83 \%$ \\
\cline { 2 - 9 } & Remoção & $97 \%$ & 347 & 27,5 & 9,1 & 3,0 & 73,4 \\
\hline $\begin{array}{c}\text { Permeaditativo) } \\
\text { (Filtração com } \\
\text { microfiltração) }\end{array}$ & $\begin{array}{c}\text { Concentração } \\
\text { (mg/L) }\end{array}$ & 0,36 & 253 & 36,8 & 3,0 & 1,9 & 60,2 \\
\hline
\end{tabular}

Similarmente ao observado para a DAM, nota-se que a NF é bastante eficiente para retenção de 
sólidos, condutividade e íons do efluente EF. O sistema foi capaz de reter 99\% do principal íon presente no efluente, o sulfato, gerando um permeado com concentrações baixas, próximas a 30 $\mathrm{mg} / \mathrm{L}$. As eficiências de retenção de poluentes aumentaram a medida que o pré-tratamento aplicado se tornava mais aprimorado. Isso pode ser justificado pela adsorção de íons na torta formada sobre o filtro/microfiltração, aumentando sua retenção global no sistema.

A concentração de arsênio no efluente bruto é bastante elevada, próxima a $500 \mathrm{mg} / \mathrm{L}$, e a membrana de NF foi capaz de reter entre 83 e $87 \%$ desse contaminante, de forma que a concentração no permeado ainda é elevada (entre 60 e $81 \mathrm{mg} / \mathrm{L}$ ). Concluiu-se que o uso de membranas de osmose inversa, mais densas que as de $\mathrm{NF}$, duplo estágio de filtração por membranas ou ajuste do $\mathrm{pH}$ da alimentação será necessário para adequar as características do permeado ao reuso ou lançamento nos corpos d'água. Nota-se também que o tipo de pré-tratamento aplicado influencia a retenção de arsênio, sendo que quanto mais aprimorado maior é a eficiência de retenção. Esses dados mostram a importância da escolha do pré-tratamento para o desempenho global do sistema de tratamento.

As concentrações de diversos metais do EF bruto e do permeado da NF após pré-tratamento com micro e nanofiltração foram quantificadas. Os resultados dos principais metais estão contidos na Tabela 4.

Tabela 4 - Concentração dos principais metais do EF bruto e do permeado da NF com pré-tratamento com MF

\begin{tabular}{|c|c|c|c|}
\hline \multirow{2}{*}{ Metal } & \multicolumn{2}{|c|}{ Concentração (mg/L) } & \multirow{2}{*}{$\begin{array}{c}\text { Eficiência de } \\
\text { remoção }\end{array}$} \\
\cline { 2 - 3 } & EF & Permeado & $100 \%$ \\
\hline Alumínio $(\mathrm{mg} / \mathrm{L})$ & 99,4 & 0,19 & $100 \%$ \\
\hline Cálcio $(\mathrm{mg} / \mathrm{L})$ & 453 & 1,52 & $96 \%$ \\
\hline Cobre $(\mathrm{mg} / \mathrm{L})$ & 12,6 & 0,46 & $99 \%$ \\
\hline Ferro $(\mathrm{mg} / \mathrm{L})$ & 155 & 1,62 & $>99 \%$ \\
\hline Magnésio $(\mathrm{mg} / \mathrm{L})$ & 190 & $<0,5$ & $100 \%$ \\
\hline Manganês $(\mathrm{mg} / \mathrm{L})$ & 25,3 & 0,07 & $>99 \%$ \\
\hline Potássio $(\mathrm{mg} / \mathrm{L})$ & 35,5 & $<0,25$ & $98 \%$ \\
\hline Zinco $(\mathrm{mg} / \mathrm{L})$ & 41,9 & 0,63 & \\
\hline
\end{tabular}

Observa-se presença acentuada de cálcio, ferro, magnésio e alumínio, além de cobre, manganês, potássio e zinco na amostra de EF bruto, superior ao encontrado para a DAM. Esses metais são liberados na forma de cátions metálicos no processo de ustulação e acabam sendo recolhidos no efluente do processo. Todos esses compostos foram retidos pela membrana de NF, que apresentou eficiências de remoção superiores a $95 \%$.

\section{CONCLUSÃO}




\section{9 a 22 de outubro de 2014 \\ Florianópolis/SC}

Conclui-se que a NF é um sistema de tratamento adequado para os dois efluentes estudados, uma vez que as eficiências de remoção de sólidos (> 80\%), condutividade (> 96\%), sulfato (> 99\%) e cálcio (> 99\%), principais contaminantes dos efluentes, foram bastante elevadas. Os resultados mostraram que a filtração das duas águas residuárias estudadas não acarreta grande incrustação da membrana de NF, mesmo quando o efluente bruto, sem pré-tratamento, é utilizado. O fluxo de efluente variou entre 62 e $90 \%$ do fluxo da membrana limpa com água. Para a DAM, apesar de o prétratamento não ter influenciado significativamente o desempenho da $\mathrm{NF}$ em termos de fluxo de permeado, a adoção de um pré-tratamento mais eficiente (microfiltração) levou a uma melhora da qualidade do permeado em todos os aspectos físico-químicos analisados. Já para o EF, a aplicação de microfiltração como pré-tratamento ocasionou não só aumento da qualidade do efluente tratado, mas também elevação do fluxo de permeado médio. Ressalta-se a necessidade de

\section{AGRADECIMENTOS}

Os autores agradecem à CAPES pelas bolsas de pós-graduação fornecidas.

\section{REFERENCIAS}

ACERO, J. L.; BENITEZ, F. J.; LEAL, A. I.; REAL, F. J.; TEVA, F. Membrane filtration technologies applied to municipal secondary effluents for potential reuse. J. Hazard. Mat., v. 177, n. 1-3, p. 390-398, 2010.

BORMA, L. S.; SOARES, P. S. M. Drenagem Ácida e gestão de resíduos sólidos de mineração. In: TRINDADE, B. E.; BARBOSA FILHO, O. (Ed.) Extração de Ouro - Princípios, tecnologia e meio ambiente. Rio de Janeiro: CETEM 2002. p. 243-266.

HABERT, A.C.; BORGES, C.P.; NOBREGA, R. Escola Piloto em EngenhariaQuímica: Processos de separação com membranas. Programa de Engenharia Química, COPPE/UFRJ, Rio de Janeiro, RJ, Brasil, 2006.

KONTOPOUlOS, A. Acid mine drainage control. In: Castro, S.H., Vergara F. e Sánchez, M.A., (Eds.). Effluent treatment in the Mining Industry, University of Concepción, Chile.p.57-118. 1998.

KRIEG, H.M.; MODISE, S.J.; KEIZER, K.; NEOMAGUS, H.W.J.P. Salt rejection in nanofiltration for single and binary salt mixtures in view of sulphate removal. Desalination, v. 171, p. 205-2015, 2004.

NGUYEN, C.M.; BANG, S.; CHO, J.; KIM, K-W. Performance and mechanism of arsenic removal from water by a nanofiltration membrane, Desalination, v. 245, p. 82-94, 2009.

SHU, L.; WAITE, T. D.; BLISS, P. J.; FANE, A.; JEGATHEESAN, V. Nanofiltration for the possible reuse of water and recovery of sodium chloride salt from textile effluent. Desalination, $\mathrm{v}$. 172, n. 3, p. 235-243, 2005.

SILVA, R. D. R. Tratamento de drenagens ácidas de minas pelo processo nfsl - neutralização, floculação e decantação lamelar. Dissertação apresentada ao Programa de Pós-Graduação em Engenharia de Minas, Metalúrgica e de Materiais da Universidade Federal do Rio Grande do Sul, 2009. 